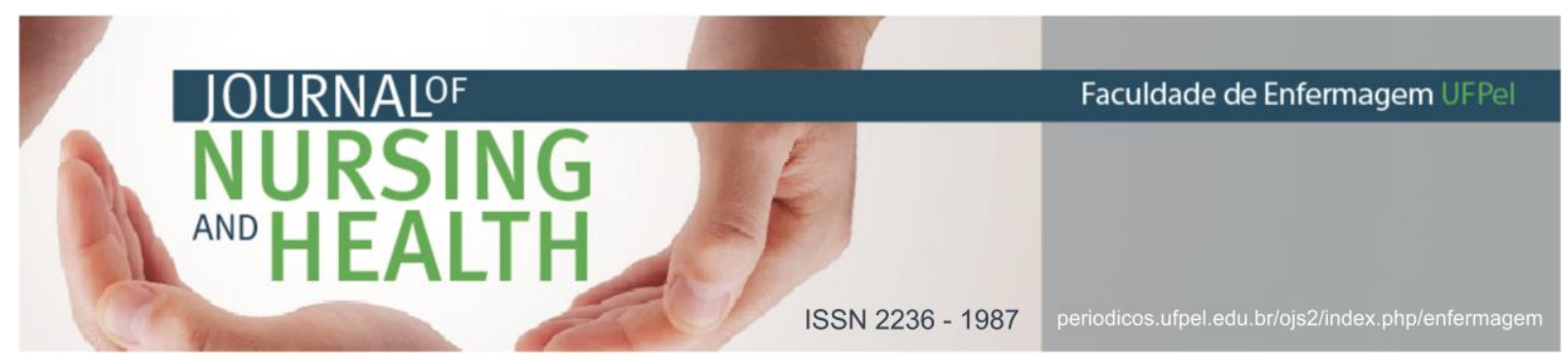

ARTIGO DE REVISÃO

\title{
Uma nova visão acerca da experiência de ouvir vozes
}

\author{
A new vision about the experience of hearing voices \\ Una nueva visión acerca de la experiencia de oír voces
}

Souza, Thylia Teixeira ${ }^{1}$; Couto, Maria Laura de Oliveira²; Kantorski, Luciane Prado ${ }^{3}$

Como citar este artigo: Souza TT, Couto MLO, Kantorski LP. Uma nova visão acerca da experiência de ouvir vozes. J. nurs. health. 2018;8(n.esp.):e188406

\section{RESUMO}

Objetivo: contextualizar o conhecimento acerca da temática da experiência de ouvir vozes. Métodos: trata-se de uma revisão sistematizada, para compreensão da temática, realizada nas bases de dados SciELO, LILACS e PubMed, em novembro de 2017, sendo selecionados 15 artigos científicos para este estudo. Resultados: temas como o Movimento dos Ouvidores de Vozes, a figura do ouvidor de voz, a fenomenologia da escuta das vozes, a experiência de ouvir vozes em diferentes culturas, estratégias utilizadas no enfrentamento e o Grupo de Ouvidores de vozes foram abordados. Considerações finais: é evidente a grande transformação a partir do surgimento do Movimento dos Ouvidores de Vozes e seus precursores, sendo importante os serviços de saúde mental compreenderem as implicações deste movimento para produção de novas formas de cuidados mais humanos.

Descritores: Alucinações; Esquizofrenia; Psiquiatria.

\section{ABSTRACT}

Objective: to contextualize the knowledge about the theme of the experience of hearing voices. Methods: it is a systematized review, to understand the theme and, done in databases SCIELO, LILACS and PubMed, in November 2017, being selected 15 scientific papers for this study. Results: themes such as the Voice Hearing Movement, the figure of the voice hearer, the phenomenology of hearing voices, the experience of hearing voices in different cultures, strategies used in the confrontation and the Group of Voice Hearing were addressed. Final considerations: it is evident the great transformation from the appearance of the Voice Hearing Movement and their precursors, being important that mental health services understand the implications of this movement for the production of new more humane forms of care.

Descriptors: Hallucinations; Schizophrenia; Psychiatry.

\footnotetext{
1 Graduanda em Enfermagem. Universidade Federal de Pelotas (UFPEL). E-mail: thyliasouza@hotmail.com http: / / orcid.org/0000-0002-7086-0853

2 Psicóloga. Universidade Federal de Pelotas (UFPEL). E-mail: marialauradeoliveiracouto@gmail.com http: / / orcid.org/0000-0002-5103-3000

${ }^{3}$ Enfermeira. Doutora em Enfermagem. Universidade Federal de Pelotas (UFPEL). E-mail: kantorski@uol.com.br http: / /orcid.org/0000-0001-9726-3162
} 


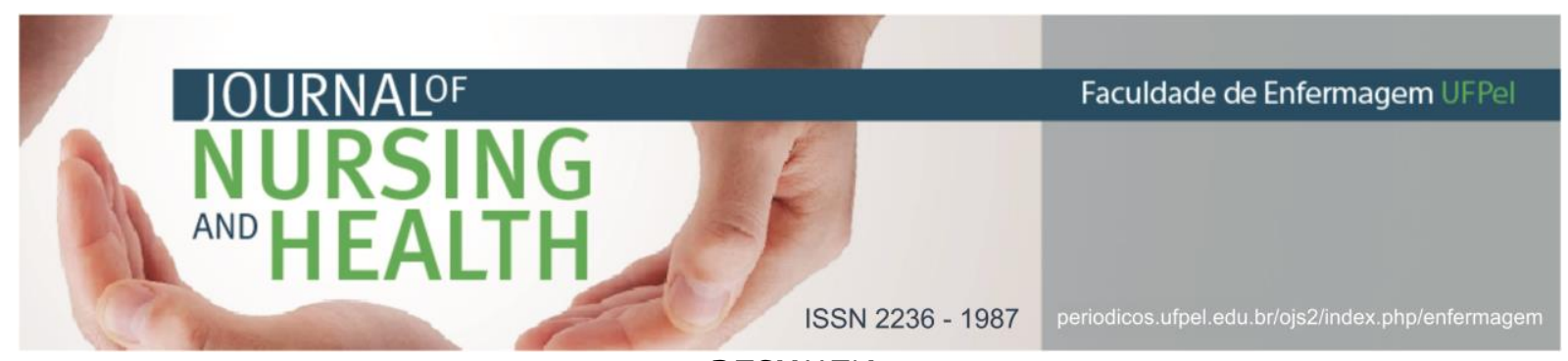

RESUMEN

Objetivo: contextualizar el conocimiento acerca del tema de la experiencia de oír voces. Métodos: es una revisión sistematizada, para la comprensión del tema, realizado en las bases de datos SciELO, LILACS y PubMed, en noviembre de 2017, siendo seleccionados 15 artículos científicos para este estudio. Resultados: temas como el Movimiento de los Oidores de Voces, la figura del oidor de voz, la fenomenología de la escucha de las voces, la experiencia de oír voces en diferentes culturas, estrategias utilizadas en el enfrentamiento y el Grupo de Oidores de voces fueron abordados. Consideraciones finales: es evidente la gran transformación a partir del surgimiento del Movimiento de los Oidores de Voces y sus predecesores, haciéndose importante que los servicios de salud mental comprendan las implicaciones de éste movimiento para la producción de nuevos modos de cuidado más humanizados.

Descriptores: Alucinaciones; Esquizofrenia; Psiquiatría.

\section{INTRODUÇÃO}

Ouvir vozes que outras pessoas não ouvem é uma experiência compartilhada por diversas pessoas e pode possuir diferentes significados, além de ser vivenciada em diversos contextos socioculturais e em diferentes períodos históricos. ${ }^{1}$

Figuras muito conhecidas, como Gandhi, Virginia Woolf, Sócrates dentre outros tinham essa experiência de ouvir vozes associada à iluminação espiritual e santidade. ${ }^{2}$ Contudo, com o advento da psiquiatria, a experiência de ouvir vozes, que acomete cerca de $4 \%$ a $10 \%$ da população em todo o mundo, passou a ser socialmente estigmatizada e indesejada. ${ }^{3}$

O movimento dos ouvidores de vozes teve início na Holanda por volta de 1987 com Patsy Hage que era paciente do psiquiatra Marius Romme. Patsy Hage tinha 30 anos, com diagnóstico de esquizofrenia e ouvia vozes. Estas eram destrutivas e negativas, faziam-na proibições e, por vezes, dominavam-na completamente. Mesmo com o uso de antipsicóticos, nada obtinha o efeito desejado que era de reduzir o número ou $\mathrm{a}$ insistência das vozes. Com todos esses acontecimentos, Patsy falava muito para seu psiquiatra sobre suicídio e Marius pensando que talvez não tivesse mais como ajudar a sua paciente, deu a ela um livro intitulado "As origens da consciência e a quebra da mente bicameral" de Julian Jaynes. Esse livro apresenta a divisão da mente em duas câmaras, uma humana e outra divina, fazendo a relação das vozes com o divino e começando a lidar com as mesmas enquanto um dom. ${ }^{4-5}$

Como consequência, Patsy contribuiu de maneira muito importante para que Marius Romme aceitasse a audição de vozes enquanto uma experiência passível de interpretação, e começasse a realizar reuniões com ela e outros ouvidores. ${ }^{4-5}$

A psiquiatria em suas abordagens convencionais ignora o significado da experiência do ouvidor de voz, concentrando-se apenas na remoção dos sintomas (alucinações auditivas) pelo uso de medicações antipsicóticas. ${ }^{6} 0$ modelo biomédico tradicional lida com esta experiência e a trata como um tabu, como algo que 


\section{ISSN 2236 - 1987}

não merece ter a importância em ser dialogado, compreendido em todos os aspectos emocionais e sociais da vida de cada ouvidor. Assim, acaba por ignorar o fato de que ouvir vozes possui um significado diferente para cada ouvidor e interfere de formas diferentes na vida de cada um deles.

A comunicação entre o ouvidor de vozes e o profissional de saúde geralmente é desencorajada, devido à crença equivocada de que falar sobre a experiência das vozes pode estimular delírios e emoções que ficarão fora de controle. $^{7}$

0 entendimento acerca da experiência de ouvir vozes dá importantes pistas clínicas, sugerindo que criar condições para que o sujeito ouvidor de vozes possa se apropriar das suas experiências alucinatórias, ressignificando-as, pode ser um caminho para transformar o caráter doloroso e alienante que frequentemente marca este tipo de vivência. ${ }^{1}$

0 artigo tem como objetivo contextualizar a construção do conhecimento acerca da temática da experiência de ouvir vozes.

\section{MATERIAIS E MÉTODOS}

Esta revisão sistematizada teve como objetivo construir um conhecimento acerca da experiência de ouvir vozes a fim de compreender a percepção desta experiência em um novo contexto, desvinculado ao da psiquiatria tradicional. A busca foi feita no mês de novembro de 2017 e rastreou estudos publicados nos últimos 10 anos - outubro de 2007 a outubro de 2017 - no Brasil e no exterior.

As bases de dados utilizadas foram Scientific Electronic Library Online (SciELO), Literatura Latinoamericana e do Caribe em Ciências da Saúde (LILACS) e Publisher Medline (PubMed). Foram utilizados os termos: auditory hallucination e voice hearing. Para todas as bases de dados foram considerados os filtros: literatura científica dos últimos dez anos, realizados com humanos e publicados nos idiomas português, inglês e espanhol.

Um total de 2715 estudos foram rastreados através das buscas. Destes, 2669 estudos foram descartados por título ou por não conter o texto completo disponível. Outros 29 foram descartados por resumo não contemplar a temática escolhida para a pesquisa e 2 por serem duplicados. Foram selecionados ao fim 15 estudos para serem lidos na íntegra. A figura 1 explana por meio de um fluxograma o percurso para seleção dos artigos nas bases de dados. 


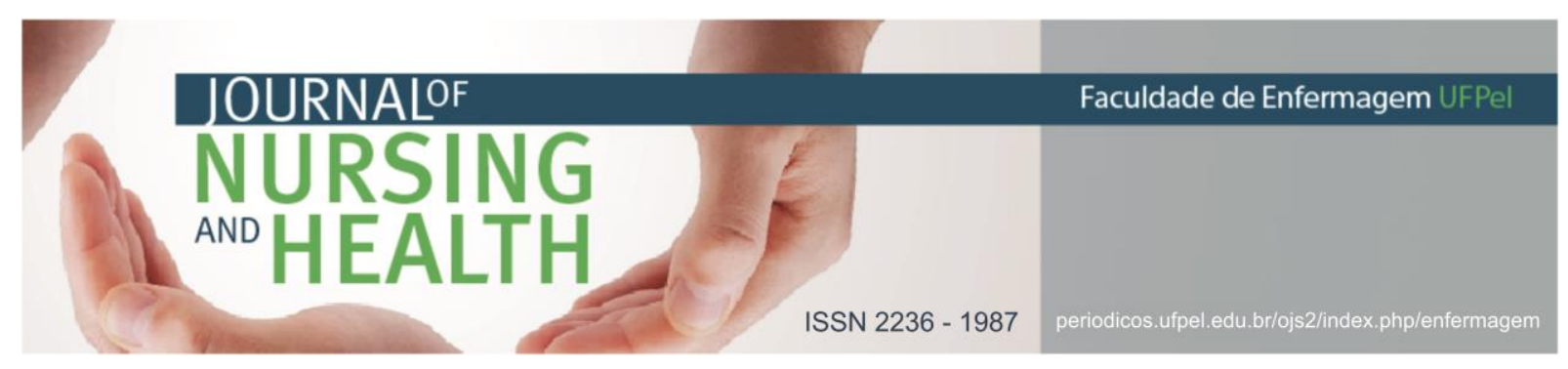

Figura 1: Fluxograma da busca na SciELO, Lilacs e Pubmed, da exclusão e seleção dos artigos.

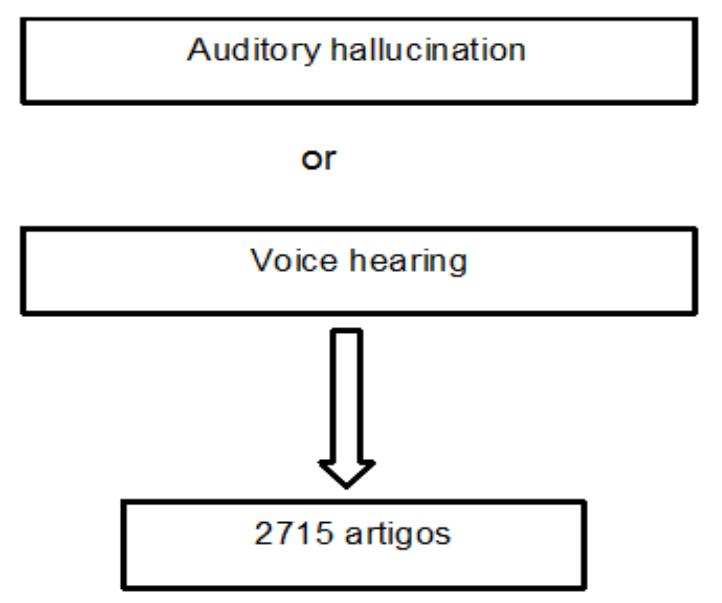

Filtro: Publicações dos últimos 10 anos; Humanos; Inglês; Português; Espanhol.

2669 descartados por título ou por não conter o texto completo
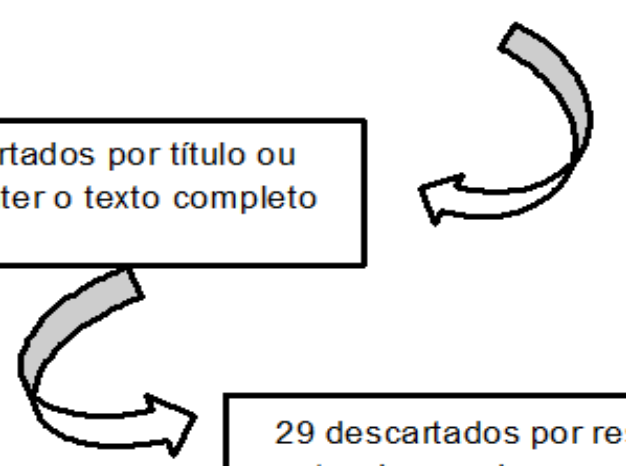

29 descartados por resumo não
estar de acordo com a temática

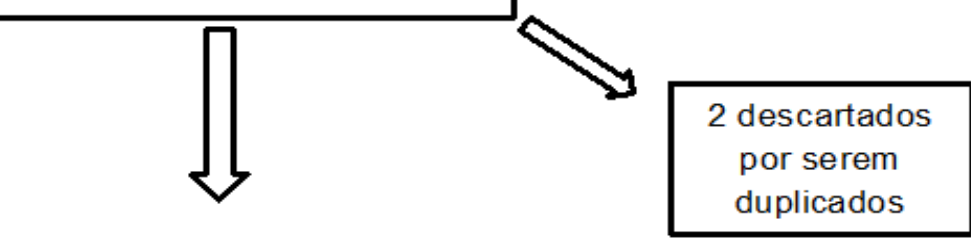

15 artigos

selecionados para ler na íntegra 


\section{RESULTADOS}

Esta revisão é baseada num total de 15 estudos. Todos tiveram suas principais características coletadas por meio de um instrumento próprio dispostos na Figura 2 contendo: autores, local do estudo, ano, metodologia utilizada, objetivos e principais resultados.

Figura 2: Estudos rastreados por meio da revisão sistematizada dispostos por: Autor/ País/ Ano, Metodologia, Objetivo e Principais Resultados.

\begin{tabular}{|c|c|c|c|}
\hline $\begin{array}{c}\text { Autor/ } \\
\text { País/ Ano }\end{array}$ & Metodologia & Objetivo & Principais Resultados \\
\hline $\begin{array}{l}\text { Barros OC; } \\
\text { Júnior ODS. } \\
\text { / Brasil/ } \\
2014\end{array}$ & $\begin{array}{l}\text { Estudo qualitativo } \\
\text { com observação } \\
\text { netnográfica }\end{array}$ & $\begin{array}{l}\text { ldentificar como os } \\
\text { ouvidores de vozes criam } \\
\text { estratégias para } \\
\text { compartilhar sua vivência } \\
\text { no ambiente virtual na } \\
\text { busca acerca da } \\
\text { experiência de ouvir } \\
\text { vozes. }\end{array}$ & $\begin{array}{l}\text { Através da netnografia demonstra que o } \\
\text { ambiente virtual é propicio para troca de } \\
\text { experiências entre os ouvidores } \\
\text { enfatizando sua relação com a } \\
\text { medicação e a forma de lidar com as } \\
\text { vozes. }\end{array}$ \\
\hline $\begin{array}{lr}\text { Muñoz } & \text { NM } \\
\text { et } & \text { al./ } \\
\text { Brasil/ } & 2011\end{array}$ & $\begin{array}{l}\text { Estudo qualitativo } \\
\text { tipo estudo de caso }\end{array}$ & $\begin{array}{l}\text { Verificar a construção de } \\
\text { narrativas sobre a } \\
\text { audição de vozes } \\
\text { aplicativo a um grupo de } \\
\text { ouvidores de vozes. }\end{array}$ & $\begin{array}{l}\text { O grupo é um importante dispositivo na } \\
\text { construção de soluções singulares e de } \\
\text { uma comunidade de trabalho voltada } \\
\text { para uma experiência que não é passível } \\
\text { de ser compartilhada pelos demais } \\
\text { frente à sociedade. }\end{array}$ \\
\hline $\begin{array}{l}\text { Barbero } \\
\text { MAM et al./ } \\
\text { Espanha/ } \\
2017\end{array}$ & $\begin{array}{l}\text { Estudo qualitativo } \\
\text { descritivo com } \\
\text { entrevistas em } \\
\text { profundidade }\end{array}$ & $\begin{array}{l}\text { Explorar as contribuições } \\
\text { de um grupo de ouvidores } \\
\text { de vozes. }\end{array}$ & $\begin{array}{l}\text { A participação no grupo de ouvidores de } \\
\text { vozes tem um impacto positivo na vida } \\
\text { do ouvidor, pois possibilita um maior } \\
\text { controle desta experiência além de } \\
\text { promover uma visão menos negativa, } \\
\text { reduzir o medo da presença das vozes e } \\
\text { o isolamento e uma melhora na relação } \\
\text { com as vozes. }\end{array}$ \\
\hline $\begin{array}{l}\text { Luhrmann } \\
\text { TM et al./ } \\
\text { Estados } \\
\text { Unidos/ } \\
2015\end{array}$ & $\begin{array}{l}\text { Estudo qualitativo } \\
\text { baseado nas } \\
\text { entrevistas de } \\
\text { Maastricht } \\
\text { desenvolvido por } \\
\text { Marius Romme e } \\
\text { Sandra Escher e a } \\
\text { entrevista de } \\
\text { Leudar-Thomas de } \\
\text { Avaliação de vozes } \\
\text { pragmáticas. }\end{array}$ & $\begin{array}{l}\text { Realizar comparações } \\
\text { sobre a experiência de } \\
\text { ouvir vozes em três } \\
\text { culturas diferentes. }\end{array}$ & $\begin{array}{l}\text { Os participantes dos Estados Unidos } \\
\text { foram mais propensos a usar rótulos de } \\
\text { diagnóstico e relações mais negativas } \\
\text { com as vozes do que os países de Gana e } \\
\text { Índia que mostraram relações mais } \\
\text { positivas com suas vozes. }\end{array}$ \\
\hline $\begin{array}{l}\text { Europe PMC } \\
\text { Funders } \\
\text { Group } \\
\text { Author } \\
\text { Manuscript/ } \\
\text { Europa/ } \\
2013\end{array}$ & $\begin{array}{l}\text { Estudo qualitativo } \\
\text { de análise } \\
\text { documental }\end{array}$ & $\begin{array}{l}\text { Descrição do ouvidor de } \\
\text { voz. }\end{array}$ & $\begin{array}{l}\text { O ouvidor de voz possui mais do que a } \\
\text { definição de alguém que escuta vozes, } \\
\text { trata-se de uma identidade complexa } \\
\text { politicamente ressonante e carregado de } \\
\text { valores. }\end{array}$ \\
\hline
\end{tabular}


JOURNALOF

Continuação da página anterior.

\begin{tabular}{|c|c|c|c|}
\hline $\begin{array}{c}\text { Autor/ } \\
\text { País/ Ano }\end{array}$ & Metodologia & Objetivo & Principais Resultados \\
\hline $\begin{array}{l}\text { Sheffield } \\
\text { JM et al./ } \\
\text { Estados } \\
\text { Unidos/ } \\
2013\end{array}$ & $\begin{array}{l}\text { Estudo } \\
\text { quantitativo } \\
\text { exploratório de } \\
\text { corte transversal }\end{array}$ & $\begin{array}{l}\text { Estudo de comparação } \\
\text { entre ouvidores de vozes } \\
\text { e pessoas que não tem } \\
\text { essa experiência e a } \\
\text { relação com o abuso } \\
\text { sexual infantil. }\end{array}$ & $\begin{array}{l}\text { O estudo apresentou maior prevalência } \\
\text { de abuso na infância, abuso emocional e } \\
\text { físico em ouvidores de vozes do que em } \\
\text { pessoas que não possuem esta } \\
\text { experiência. }\end{array}$ \\
\hline $\begin{array}{l}\text { Docherty } \\
\text { NM et al. / } \\
\text { Estados } \\
\text { Unidos/ } \\
2015\end{array}$ & $\begin{array}{l}\text { Estudo } \\
\text { quantitativo de } \\
\text { corte transversal }\end{array}$ & $\begin{array}{l}\text { Comparação entre } \\
\text { ouvidores de vozes que } \\
\text { possuem a escuta das } \\
\text { vozes interna e } \\
\text { externamente. }\end{array}$ & $\begin{array}{l}\text { Não houve diferenças entre vozes } \\
\text { internas ou externas. Porém os que } \\
\text { tinham vozes internas possuíam relações } \\
\text { negativas com suas vozes, tinham menos } \\
\text { controle e as vozes comentavam sobre } \\
\text { eles e davam comandos além do insight } \\
\text { de serem os geradores de suas vozes. }\end{array}$ \\
\hline $\begin{array}{l}\text { McGrath JJ } \\
\text { et al./ } \\
\text { Austrália/ } \\
2015\end{array}$ & $\begin{array}{l}\text { Estudo } \\
\text { quantitativo de } \\
\text { corte transversal }\end{array}$ & $\begin{array}{l}\text { Explorar a experiência de } \\
\text { ouvir vozes em } 18 \text { países. }\end{array}$ & $\begin{array}{l}\text { A prevalência média ao longo da vida de } \\
\text { ter uma experiência psicótica foi de } \\
5,8 \% \text {, com experiências alucinantes } \\
5,2 \% \text {, sendo muito mais comuns do que } \\
\text { experiências delirantes (1,3\%). As } \\
\text { estimativas de prevalência ao longo da } \\
\text { vida foram significativamente maiores } \\
\text { entre os entrevistados em países de } \\
\text { renda média e alta do que países de } \\
\text { baixa renda, mulheres do que homens, } \\
\text { não casados do que casados, não } \\
\text { empregados e com baixa renda familiar. }\end{array}$ \\
\hline $\begin{array}{l}\text { Kalhovde } \\
\text { AM; Esltad } \\
\text { I; Talseth } \\
\text { A./ } \\
\text { Noruega/ } \\
2014\end{array}$ & $\begin{array}{l}\text { Estudo qualitativo } \\
\text { com entrevista em } \\
\text { profundidade e } \\
\text { análise } \\
\text { fenomenológica }\end{array}$ & $\begin{array}{l}\text { Compreender como os } \\
\text { ouvidores de vozes lidam } \\
\text { com a sua experiência de } \\
\text { ouvir vozes. }\end{array}$ & $\begin{array}{l}\text { Alguns participantes utilizaram } \\
\text { estratégias como tentar bloquear o som } \\
\text { da voz, esteve em diversos serviços de } \\
\text { saúde e tentou entrar em um acordo com } \\
\text { as suas vozes. }\end{array}$ \\
\hline $\begin{array}{l}\text { McCarthy- } \\
\text { Jones S et } \\
\text { al./ } \\
\text { Austrália/ } \\
2012\end{array}$ & $\begin{array}{l}\text { Estudo } \\
\text { quantitativo com } \\
\text { entrevista semi- } \\
\text { estruturada }\end{array}$ & $\begin{array}{l}\text { Compreender } \\
\text { fenômeno da escuta das } \\
\text { vozes para desenvolver as } \\
\text { suas causas. }\end{array}$ & $\begin{array}{l}\text { Os achados apresentaram que } 39 \% \text { dos } \\
\text { participantes relataram que suas vozes } \\
\text { pareciam de alguma forma ser repetição } \\
\text { de memórias anteriores e conversas que } \\
\text { tinham experimentado; } 45 \% \text { relataram } \\
\text { que o tema geral ou conteúdo do que as } \\
\text { vozes diziam era sempre o mesmo. }\end{array}$ \\
\hline $\begin{array}{l}\text { Woods A et } \\
\text { al./ Reino } \\
\text { Unido/ } \\
2014\end{array}$ & $\begin{array}{l}\text { Estudo qualitativo } \\
\text { bibliográfico }\end{array}$ & $\begin{array}{l}\text { Abordagem de forma } \\
\text { interdisciplinar para a } \\
\text { compreensão da } \\
\text { experiência de ouvir } \\
\text { vozes para o avanço nas } \\
\text { pesquisas clínicas. }\end{array}$ & $\begin{array}{l}\text { O estudo enfatiza a importância de uma } \\
\text { abordagem interdisciplinar, onde os } \\
\text { ouvidores de vozes foram analisados em } \\
\text { três níveis contextuais: cultural, social e } \\
\text { histórico; experiencial; e biográfico. } \\
\text { Incluem a informação do } \\
\text { desenvolvimento e aperfeiçoamento de } \\
\text { subtipos de alucinações dentro e entre } \\
\text { categorias de diagnóstico, pesquisa de } \\
\text { "front-loading" } \\
\text { cognitiva em neurociência } \\
\text { possibilidades sugestão de novas } \\
\text { terapêutica. }\end{array}$ \\
\hline
\end{tabular}


JOURNALOF

Continuacão da página anterior.

\begin{tabular}{|c|c|c|c|}
\hline $\begin{array}{c}\text { Autor/ } \\
\text { País/ Ano }\end{array}$ & Metodologia & Objetivo & Principais Resultados \\
\hline $\begin{array}{l}\text { Corstens D } \\
\text { et al./ } \\
\text { Países } \\
\text { Baixos/ } \\
2014\end{array}$ & $\begin{array}{l}\text { Estudo qualitativo } \\
\text { bibliográfico }\end{array}$ & $\begin{array}{l}\text { Crescimento histórico e a } \\
\text { influência do Movimento } \\
\text { dos ouvidores de vozes. }\end{array}$ & $\begin{array}{l}\text { O princípio fundamental do Movimento } \\
\text { dos Ouvidores de Vozes é a noção de que } \\
\text { ouvir vozes é uma experiência humana } \\
\text { significativa e é realizada uma discussão } \\
\text { acerca do crescimento histórico, da } \\
\text { influência do movimento e das } \\
\text { implicações dos seus valores de pesquisa } \\
\text { e prática em relação aos ouvidores de } \\
\text { vozes. O envolvimento dos ouvidores de } \\
\text { vozes na pesquisa e um maior uso de } \\
\text { abordagens narrativas e qualitativas são } \\
\text { apontadas como essenciais. }\end{array}$ \\
\hline $\begin{array}{l}\text { Laroi F et } \\
\text { al./ Estados } \\
\text { Unidos/ } \\
2014\end{array}$ & $\begin{array}{l}\text { Estudo qualitativo } \\
\text { de revisão } \\
\text { bibliográfica }\end{array}$ & $\begin{array}{l}\text { Conhecer a visão de } \\
\text { diversas culturas acerca } \\
\text { da experiência de ouvir } \\
\text { vozes. }\end{array}$ & $\begin{array}{l}\text { Os resultados mostraram que a cultura } \\
\text { realmente tem um impacto na } \\
\text { experiência, na compreensão e } \\
\text { rotulagem de alucinações e que pode } \\
\text { haver importantes teorias e } \\
\text { consequências clínicas dessa } \\
\text { observação. A cultura pode afetar o que } \\
\text { é identificado como uma alucinação e } \\
\text { que existem diferentes padrões de } \\
\text { alucinações entre as populações clínicas } \\
\text { e não clínicas. }\end{array}$ \\
\hline $\begin{array}{l}\text { Krakvik B et } \\
\text { al./ } \\
\text { Noruega/ } \\
2015\end{array}$ & $\begin{array}{l}\text { Estudo } \\
\text { quantitativo de } \\
\text { corte transversal }\end{array}$ & $\begin{array}{lr}\text { Comparação } & \text { da } \\
\text { experiência da escuta das } \\
\text { vozes numa população } \\
\text { geral em diferenças } \\
\text { grupos. }\end{array}$ & $\begin{array}{l}\text { No total, } 7,3 \% \text { da amostra relataram uma } \\
\text { prevalência ao longo da vida de escuta } \\
\text { das vozes. Pode-se observar que os } \\
\text { ouvidores que não buscaram ajuda } \\
\text { profissional, tiveram mais chances de } \\
\text { experimentar escuta das vozes com } \\
\text { conteúdo negativo, uma frequência } \\
\text { diária das vozes algém de reações } \\
\text { negativas e resistência a esta } \\
\text { experiência. }\end{array}$ \\
\hline $\begin{array}{ll}\text { Ng P; } & \text { Chun } \\
\text { RWK; } & \text { Tsun } \\
\text { A/ } & \text { Hong } \\
\text { Kong/ } & 2012\end{array}$ & $\begin{array}{l}\text { Estudo qualitativo } \\
\text { exploratório com } \\
\text { entrevista em } \\
\text { profundidade }\end{array}$ & $\begin{array}{l}\text { Formas de lidar com a } \\
\text { escuta das vozes em } \\
\text { pessoas de Hong Kong. }\end{array}$ & $\begin{array}{l}\text { Os resultados de entrevistas mostraram } \\
\text { que pessoas com esquizofrenia no } \\
\text { contexto sociocultural chinês estavam } \\
\text { lidando com a experiência de ouvir vozes } \\
\text { de diferentes maneiras, como: mudando } \\
\text { os contatos sociais, manipulando as } \\
\text { vozes e mudando a percepção e } \\
\text { significado atribuido as mesmas. }\end{array}$ \\
\hline
\end{tabular}

\section{DISCUSSÃO}

A seguir, apresentamos a discussão desenvolvida na literatura a partir da revisão sistematizada realizada enfatizando o Movimento dos Ouvidores de Vozes, a figura do ouvidor de voz, a fenomenologia da escuta das vozes, a experiência de ouvir vozes em diferentes culturas, estratégias utilizadas no enfrentamento e o Grupo de Ouvidores de vozes.

O crescimento histórico do Movimento dos Ouvidores de vozes em 


\section{JOURNALOF \\ NURSING \\ ANO HEALTH}

ISSN 2236 - 1987

sua reformulação da classificação biomédica acerca da experiência de ouvir vozes, enfatiza os valores fundamentais do movimento, que considera a escuta das vozes uma parte natural da experiência humana, uma resposta interpretável de circunstâncias sociais, emocionais e interpessoais. $^{8}$

O estudo apresentou também a figura do ouvidor de voz como um "expert por experiência" que desafia a psiquiatria tradicional e o diagnóstico, possibilitando compartilhar e ajudar os pares no enfrentamento de sua experiência. Destaca que o conceito patológico que envolve a experiência de ouvir vozes, que induz ao estigma, reduz a autoestima e é considerada como irreal, dando maior eficácia na eliminação das vozes com o uso de psicofármacos e seus perigosos efeitos colaterais. $^{8}$

Os autores enfatizam a produção escrita sobre a experiência de ouvir vozes, as diferentes abordagens sobre a mesma. Destacam o livro com histórias de sucesso de lidar com as vozes e a Entrevista Estruturada de Maastricht, a qual é uma ferramenta para tentar construir e determinar 0 que as vozes representam e o problema que elas representam. Também foram realizados congressos anuais onde especialistas por profissão e/ou por experiência apresentam novas perspectivas e um espaço seguro para compreensão desta experiência. ${ }^{8}$

Outro autor também afirma em seu estudo que o Movimento de Ouvidores de Vozes transformou a visão sobre a experiência da escuta das vozes através de Marius Romme e Patsy Hage na Holanda e no Reino Unido em sua abordagem das vozes como parte fundamental da identidade de uma pessoa. $^{2}$

Apesar da psiquiatria vincular a experiência de ouvir vozes a esquizofrenia, apresentando que dentro do sistema psiquiátrico 0 esquizofrênico nunca teve uma história de vida, poucos levam uma vida produtiva e não possuem uma história de recuperação, essa experiência tem sido abordada no seu sentido singular, no que fala sobre cada pessoa e no modo como se produz sentidos sobre ela. ${ }^{2}$

Identificar um ouvidor de voz vai além do contexto da escuta das vozes, pois nem todos compartilham das mesmas experiências, valores, crenças e histórias sendo importante que os profissionais de saúde reconheçam o Movimento dos Ouvidores de vozes e todas as suas implicações. ${ }^{2}$

Dois estudos apresentaram a fenomenologia da experiência de ouvir vozes. Um estudo com 199 participantes mostrou que $28 \%$ relataram um número incontável de vozes, sendo a localização mais frequente interna e em ambas as orelhas (75\%). Dos participantes estudados, $48 \%$ relataram em sua primeira vez ouvir vozes, $33 \%$ relataram ouvir sons não verbais e $8 \%$ ouvir os dois juntos. Com relação ao conteúdo destas vozes a maior prevalência foi de conteúdo negativo (60\%) onde apresentavam-se vozes irritadas, desagradáveis e mandonas. ${ }^{9}$

A maior parte dos participantes disse que o conteúdo eram repetições de suas experiências anteriores. Entre os sons não verbais relatados, $46 \%$ 


\section{JOURNAIOF

eram de música, $43 \%$ de toque, $29 \%$ de sons de animais, $27 \%$ de cliques, $24 \%$ de zumbidos e $10 \%$ de sons de água. Também foi enfatizada a importância de uma abordagem interdisciplinar para o fenômeno das vozes, analisando uma gama de contextos associados ao ouvidor como cultural, social e histórico, a sua experiência e a sua biografia. ${ }^{9-10}$

Alguns estudos realizaram pesquisa acerca da compreensão da escuta das vozes. Em um estudo foi analisado a experiência de ouvir vozes numa população geral de 18 países com um total de 31.261 participantes, obteve que a prevalência de experiência psicótica nessa população foi de 5,8\%; de experiências alucinantes foi 5,2\% e de experiências delirantes foi $1,3 \%{ }^{11}$

$\begin{array}{ccc}\text { Destacando } & 0 & \text { Brasil } \\ \text { isoladamente, foi realizado uma }\end{array}$ pesquisa com 548 participantes, em que $14,9 \%$ relatou ter tido alguma experiência psicótica na vida, 13,3\% relatou ter tido alguma experiência de alucinação na vida e 3,6\% relatou ter tido alguma experiência de delírio durante sua vida. ${ }^{11}$

Um estudo realizado na Noruega também avaliou uma população geral, porém com um número menor de participantes, um total de 2.533 participantes, em que $7 \%$ relataram que já escutaram vozes pelo menos uma vez na vida. Destes $7 \%, 6 \%$ não buscaram ajuda profissional e maior prevalência com relação à idade da escuta das vozes, que foi acima de 30 anos (14\%). ${ }^{12}$

Um autor analisou a existência de uma diferença na escuta de vozes internas e externas, e os resultados não apresentaram nenhuma distinção, porém os ouvidores que tinham vozes internas relataram maior conteúdo negativo que causava angústia e perturbação em suas vidas, vozes que comentavam e ordenavam a ferir-se e a matar outras pessoas e também tinham menos controle sobre suas vozes e as mesmas tinham maior duração. ${ }^{13}$

Um estudo realizado nos Estados Unidos procurou a relação entre o abuso infantil e a experiência de ouvir vozes com 114 participantes que ouviam vozes e 81 participantes que não tinham esta experiência. Os resultados mostraram que $70 \%$ dos pacientes que ouviam vozes haviam sofrido abuso na infância, sendo uma prevalência maior do que os participantes que não escutavam vozes. Ainda foi feita uma divisão em 5 sub escalas sendo apresentadas em $30 \%$ abuso físico, 39\% abuso sexual, $69 \%$ abuso emocional, 44\% negligência emocional e $34 \%$ negligência física. ${ }^{14}$

Outro ponto muito importante explorado por alguns estudos, foi 0 entendimento da experiência de ouvir vozes em diferentes culturas. Um estudo realizado em três cidades de diferentes países (Estados Unidos, Índia e Gana) foram comparados a sua compreensão acerca da escuta das vozes. A amostra americana demonstrou a utilização de mais rótulos de diagnóstico psiquiátrico e relações mais negativas com suas vozes. Já a amostra da Índia e Gana apresentaram relações mais positivas com suas vozes, pois entendiam que as vozes eram divindades, como Deus e 


\section{IOURNAIOF

espíritos que dão orientação e proteção. ${ }^{15}$

Uma revisão bibliográfica apresentou que a cultura molda em diversas dimensões a escuta das vozes: na identificação, na experiência, no conteúdo, na frequência, no significado, como os ouvidores respondem a essa experiência e nos sentimentos expressos por eles. Trazem alguns exemplos como um povo indígena do Amazonas que entende as vozes como um guia espiritual e servem como orientação ou os cristãos que identificavam como Deus ou Satanás. Também relataram o avanço dos séculos, pois no século 19 tornava-se aceitável a capacidade de ouvir Deus ou falar com os mortos onde 0 espiritismo se tornou um movimento popular, já no século 20 é descrito exclusivamente como um sinal de doença mental. ${ }^{16}$

Um estudo também mostrou como é vista a experiência de ouvir vozes no contexto sociocultural chinês onde existe uma crença religiosa popular de retribuição pelo pecado na forma de um espírito mau que vai invadir o corpo, além da ênfase no desequilíbrio entre o yin e yang que pode ocasionar em doença ou psicopatologia. ${ }^{17}$

Uma questão que norteia o Movimento dos Ouvidores de Vozes a partir desta nova perspectiva de compreender o fenômeno de ouvir vozes é entender as formas de lidar com esta experiência e como esta experiência se reflete na vida do ouvidor. Uma pesquisa realizada na Espanha, onde foram utilizadas entrevistas em profundidade, os participantes relataram em sua primeira experiência com a escuta das vozes sentimentos como impotência, incerteza e desesperança com relação ao futuro o que ocasionou no isolamento e desconfiança devido a falta de informação com relação a sua experiência. Foi enfatizado o medo nos discursos ao falar dos profissionais e dos dispositivos de saúde mental onde foram tratados pela violação dos seus direitos humanos, o que contribuiu para o aumento do sofrimento. ${ }^{18}$

Outro ponto que foi mencionado pelos entrevistados, foi a qualidade do apoio recebido, visto que o serviço de saúde mental é a porta de entrada depois da primeira experiência da escuta das vozes. E o retorno que o serviço oferece ao ouvidor é somente o diagnóstico, a severidade e a cronicidade dos sintomas além do tratamento com 0 uso de antipsicóticos. Não fornece assim a erradicação da ameaça e o medo que muitas vezes estão associados a esta experiência. Os entrevistados também relataram que se tornaram passivos a sua experiência, pois os serviços de saúde mental minavam a sua capacidade de controlar o que acontece e sobre sua própria vida. ${ }^{18}$

Um estudo realizado na Noruega trouxe ainda mais apontamentos acerca de como é esta experiência para alguns ouvidores. Os participantes relataram sentir-se com a sua confiança violada por parte dos profissionais por eles compartilharem esta experiência com os seus familiares sem o seu consentimento, porém por outro lado, alguns participantes relataram que acabaram por depositar confiança aos profissionais porque os mesmos o questionaram sobre as vozes 


\section{JOURNAIOF

e que isso deu a sensação de alívio, visto que isto nunca havia sido mencionado dentro do serviço. ${ }^{19}$

Os participantes também acabaram por relatar o seu medo pela perda da custódia de seus filhos caso mencionassem sobre sua experiência de ouvir vozes. Foi mencionado sobre a falta de informação de como lidar com as vozes e ligaram isso fortemente ao preconceito estabelecido aos doentes mentais. 0 estudo também pesquisou acerca do uso da medicação, onde mostrou que grande parte dos entrevistados renunciou ao uso prolongado e reduziu as doses da sua medicação devido aos fortes efeitos colaterais dos antipsicóticos diminuindo a sua capacidade de pensar, falar e sentir. ${ }^{19}$

Estudos em Hong Kong e na Noruega apresentaram formas de lidar com a experiência de ouvir de vozes a partir de relatos dos participantes. Os resultados mostraram diversas estratégias elaboradas pelos ouvidores para lidar com suas vozes como aceitar a existência das vozes, ignorar as vozes, definir limites para as vozes, anotar o conteúdo das vozes, ligar o rádio, fazer caminhadas, distrair com outras atividades como as tarefas cotidianas, ler e ouvir música. ${ }^{17-19}$

Alguns autores enfatizam em seus estudos a importância dos Grupos de Ouvidores de Vozes como uma estratégia e um meio positivo de avançar diante desta experiência, elaborando soluções singulares contribuindo com suporte entre os pares, respeito, compreensão, carinho e solidariedade além de restaurar a capacidade de confiança nos outros promovendo a aceitação e convivência com as vozes. A criação de uma comunidade de trabalho voltada para essa experiência que essencialmente é evidenciada por não ser possível de ser compartilhada com o restante da sociedade mostra-se positiva. ${ }^{18-20}$

0 ambiente virtual como um espaço de troca de experiências entre os ouvidores na sua relação com o uso de medicações e formas de lidar com as vozes numa criação de laços sociais e uma nova maneira de estar no mundo. ${ }^{1}$

A fim de explorar outros aspectos com relação ao fenômeno de ouvir vozes, é necessário pesquisas nesta área no Brasil com o propósito de fomentar ainda mais o conhecimento acerca desta temática.

\section{CONSIDERAÇÕES FINAIS}

A partir desta revisão sistematizada pode-se concluir a grande transformação com 0 surgimento do Movimento dos Ouvidores de Vozes com seus precursores Marius Romme e Patsy Hage, nesta nova visão acerca da experiência de ouvir vozes, que engloba a história de vida a fim de explorar os traumas ocorridos vendo isto como uma vivência pessoal de cada ouvidor.

Os serviços de saúde mental devem dispor do conhecimento e das implicações do Movimento de Ouvidores de Vozes para melhorar ainda mais a qualidade do seu cuidado prestado, auxiliando na recuperação e na elaboração de estratégias que possam lidar com esta experiência da escuta das vozes como apresentado em diversos estudos como o Grupo de 


\section{NURSING \\ AND HEALTH}

Ouvidores de Vozes, que tem sido uma importante ferramenta de ajuda mútua neste processo de enfretamento.

\section{REFERÊNCIAS}

1 Barros OC, Serpa Júnior OD. Ouvir vozes: um estudo sobre a troca de experiências em ambiente virtual. Interface (Botucatu, Online) [Internet]. 2014[acesso em 2018 ago 11];18(50):557-69. Disponível em: http://www.scielo.br/pdf/icse/v18n5 0/1807-5762-icse-1807-

576220130680.pdf

2 Europe PMC Funders Group Author Manuscript. The Voice-Hearer. J ment health [Internet], 2013[cited 2018 Aug 11];22(3):1-8. Available from: https://www.ncbi.nlm.nih.gov/pmc/a rticles/PMC3836250/

3 Baker P. Abordagem de ouvir vozes: treinamento Brasil. Tradução de Lindsei Ferreira Lansky. São Paulo: CENAT; 2016:72.

4 Contini C. Ouvir Vozes: Manual de Enfrentamento. In: Kantorski LP; Antonacci MH. Prefácio à Edição Brasileira. Pelotas: Cópias Santa Cruz; 2017.

5 Romme M, Escher S. Na companhia das vozes: para uma análise da experiência de ouvir vozes. Lisboa: Editorial Estampa; 1997.

6 Romme MA, Escher AD. Hearing voices. Schizophr bull. 1989;15(2): 209-16.

7 Corstens D, Escher S, Romme $M$. Accepting and working with voices: the
ISSN 2236 - 1987

Maastricht approach. In: Moskowitz A, Schafer I, Dorahy MJ. (Eds.). Psychosis, trauma and dissociation: emerging perspectives on severe psychopathology. Oxford, UK: WileyBlackwell; 2008:319-32.

8 Corstens D, Longden E, MccarthyJones S, Waddingham R, Neil Thomas $N$. Emerging perspectives from the hearing voices movement: implications for research and practice. Schizophr bull [Internet]. 2014[cited 2018 Aug 11];40(4):285-94. Available from: https://www.ncbi.nlm.nih.gov/pmc/a rticles/PMC4141309/

9 Mccarthy-Jones S, Trauer T, Mackinnon A, Sims E, Thomas N, Copolov Dl. A new phenomenological survey of auditory hallucinations: evidence for subtypes and implications for theory and practice. Schizophr bull [Internet]. 2014[cited 2018 Aug 11];40(1):225-35. Available from: https: / /www.ncbi.nlm.nih.gov/pmc/a rticles/PMC3885292/

10 Woods A, Jones N, Bernini M, Callard F, Alderson-Day B, Badcock J, Bell V, et al. Interdisciplinary approaches to the phenomenology of auditory verbal hallucinations. Schizophr bull [Internet]. 2014[cited 2018 Aug 11];40(4):246-54. Available from: https: / /www.ncbi.nlm.nih.gov/pmc/a rticles/PMC4141308/

11 McGrath JJ, Saha S, Al-Hamzawi A, Alonso J, Bromet EJ, Bruffaerts R, et al. Psychotic experiences in the general population: a cross-national analysis based on 31,261 respondents from 18 countries. JAMA Psychiatry [Internet]. 2015[cited 2018 Aug 11];72(7):697-705. Available from: 
https://www.ncbi.nlm.nih.gov/pmc/a rticles/PMC5120396/

12 Krakvik B, Laroi F, Kalhovde AM, Hugdahl K, Kompus K, Salvesen et al. Prevalence of auditory verbal hallucinations in a general population: a group comparison study [Interent]. Scand j psychol [cited 2018 Aug 11]. 2015;56:508-15. Available from: https://onlinelibrary.wiley.com/doi/f ull/10.1111/sjop.12236

13 Docherty NM, Dinzeo TJ, Mccleery A, Bell EK, Shakeel MK, Moe A. Internal versus external auditory hallucinations in schizophrenia: symptom and course correlates. Cogn neuropsychiatry [Internet]. 2015[cited 2018 Aug 11];20(3):187-97. Available from: https://www.ncbi.nlm.nih.gov/pmc/a rticles/PMC4372463/

14 Sheffield JM, Williams LE, Blackford JU, Heckers S. Childhood sexual abuse increases risk of auditory hallucinations in psychotic disorders. Compr psychiatry [Internet]. 2013[cited 2018 Aug 11];54(7):1098104. Available from: https://www.ncbi.nlm.nih.gov/pubm ed/23815887

15 Luhrmann TM, Padmavati R, Tharoor $\mathrm{H}$, Osei A. Differences in voice-hearing experiences of people with psychosis in the USA, India and Ghana: interviewbased study. $\mathrm{Br}$ j psychiatry [Internet]. 2015[cited 2018 Aug 11];206:41-4. Available from: https://www.cambridge.org/core/jou rnals/the-british-journal-ofpsychiatry/article/differences-invoicehearing-experiences-of-peoplewith-psychosis-in-the-usa-india-andghana-interviewbased-
study/A5DA3DC9FE1BD05439D676F182 2DD4DD

16 Laroi F, Luhrmann, TM, Bell V, Christian Jr WA, Deshpande $\mathrm{S}$, Fernyhough $\mathrm{C}$ et al. Culture and hallucinations: overview and future directions. Schizophr bull [Internet]. 2014[cited 2018 Aug 11];40(4):213-20. Available

from: https: / /academic.oup.com/schizophr eniabulletin/article/40/Suppl_4/S213 /1874317

17 Ng P, Chun RK, Tsun A. Recovering from hallucinations: a qualitative study of coping with voices hearing of people with schizophrenia in Hong Kong. Scientific world journal [Internet]. 2012[cited 2018 Aug 11];8. Available form:

https://www.ncbi.nlm.nih.gov/pmc/a rticles/PMC3529899/

18 Barbero MAM, Pereira MCC, Villalba GP, Hernández MVM. Escuchando la voz de las personas que escuchan voces. Rev asoc esp neuropsiquiatr [Internet]. 2017[cited 2018 Aug 11];37(131):3961. Available from: http://www.revistaaen.es/index.php/ aen/article/view/16989/16859

19 Kalhovde AM, Elstad I, Talseth A. "Sometimes I walk and walk, hoping to get some peace." Dealing with hearing voices and sounds nobody else hears. Int $j$ qual stud health well-being [Internet]. 2014[cited 2018 Aug 11];112. Available from: https: //www.ncbi.nlm.nih.gov/pmc/a rticles/PMC3968296/

20 Muñoz NM, Serpa Júnior OD, Leal EM, Dahl CM, Oliveira IC. Pesquisa Clínica em saúde mental: o ponto de 


\section{NURSING AND}

vista dos usuários sobre a experiência de ouvir vozes. Estud psicol. [Internet]. 2011[acesso em 2018 ago 11];16(1):83-9. Disponível em: http://www.scielo.br/pdf/epsic/v16n 1/a11v16n1.pdf

Data de publicação: 19/09/2018 